\title{
Diagnostic efficacy of Striae Gravidarum in predicting intraperitoneal adhesions and uterine scar thickness in women undergoing repeat caesarean section
}

\author{
Akanksha Mohanty*, H. P. Anand \\ Department of Obstetrics and Gynaecology, Vardhman Mahavir Medical College and Safdarjung Hospital, New Delhi, \\ India \\ Received: 10 November 2020 \\ Accepted: 16 January 2021

\section{*Correspondence:} \\ Dr. Akanksha Mohanty, \\ E-mail: akanksham4394@gmail.com \\ Copyright: (c) the author(s), publisher and licensee Medip Academy. This is an open-access article distributed under \\ the terms of the Creative Commons Attribution Non-Commercial License, which permits unrestricted non-commercial \\ use, distribution, and reproduction in any medium, provided the original work is properly cited.
}

\begin{abstract}
Background: Striae gravidarum (SG) are stretch marks on the skin which develop during pregnancy. Cesarean section is one of the most common operation performed worldwide which carries a potential risk of complications due to the intra-peritoneal adhesions and thickness of previous uterine scar. The aim of this study was to find the diagnostic efficacy of striae gravidarum in predicting intra-peritoneal adhesions (IPA) and uterine scar thickness in women undergoing repeated caesarean delivery.

Methods: It was a cross-sectional study done over a period of 18 months duration. One hundred women with previous cesarean section scheduled for elective LSCS were enrolled for the study. Striae gravidarum was calculated according to the Atwal numerical scoring system. Presence of intra-peritoneal adhesions were graded intraoperatively according to modified Nair scoring system. After extraction of baby, the thickness of lower uterine segment at midpoint of lower flap of uterine incision was measured by metallic screw gauge.

Results: Significant positive correlation was seen between striae gravidarum and intra-peritoneal adhesions. A negative association was established between striae gravidarum severity and thickness of LUS. Owing to its moderately high sensitivity and low specificity in predicting IPA Grade 3 or 4 and LUS scar thickness $<3.74 \mathrm{~mm}$, striae gravidarum cannot be used as a diagnostic indicator, but can be a useful mass screening method.

Conclusions: Striae gravidarum is a zero-cost simple quick and easy technique which can be universally used with minimal intra-observer variation to predict perioperative complications in low resource settings.
\end{abstract}

Keywords: Intraperitoneal adhesions, Striae gravidarum, Uterine scar thickness

\section{INTRODUCTION}

Striae gravidarum (stretch marks) is a dermatological condition occurring in the second or third trimester of pregnancy, typically on the abdomen and breasts and less commonly on the buttocks, hips, and thighs, with an unknown etiology. There is a lack of information in the medical literature about striae, but potential risk factors such as infant birth weight, body mass index, weight gain in pregnancy, and age, among others have been proposed. ${ }^{1}$ According to Liu et al, higher risk of pelvic organ prolapse has been found in women who developed striae during pregnancy. ${ }^{2}$ Initially, the lesions are pink to violaceous and may be edematous. Over a period of time, the lesions mature into white, shiny, atrophic, and crinkly streaks that become permanent. Although it is not considered medically dangerous to the mother or the fetus, SG can incur a considerable psychological burden in affected women.

As per Atwal et al. maternal age is a very significant factor in determining the occurrence of striae 
gravidarum. ${ }^{3}$ Reports show an incidence of one in five primiparae under the age of 20 developing severe striae as compared to none over the age of 30 . An increased fragility of fibrillin in younger skin leading to fibrillin loss maybe the reason behind it. Similarly, in Marfan's Syndrome, stria is a common cutaneous manifestation, which can be attributed to the production of abnormal fibrillin. Striae gravidarum (SG) is a common, disfiguring, gestational change that affects between $55 \%$ and $90 \%$ of women. ${ }^{4}$ The overall incidence of striae gravidarum that occurred during the first pregnancy was $56 \%$.

Adhesions are an enigmatic condition with protean clinical manifestations; they are defined as abnormal fibrous connection between two anatomically different surfaces. Grossly, they appear as bands of scar-like tissue. Adhesions are troublesome complications after abdominal and pelvic surgery. Its potential sequelae may include infertility with increased risk of ectopic pregnancy, abdominal and pelvic pain, bowel obstruction, and difficult repeat surgical procedures. ${ }^{5}$ Intra-peritoneal adhesions can cause a wide range of complications during a surgery such as difficult intra-abdominal entry, increased blood loss, longer duration of surgery and injury to bladder, uterus or small intestine. In addition, prior abdominal or pelvic surgery can also increase postoperative morbidities such intestinal obstruction, female infertility and chronic pelvic pain. ${ }^{6}$ As per a study conducted by Dogan et al. normal peritoneal healing and adhesion formation can be attributed to the delicate balance between fibrin deposition and degradation. ${ }^{6}$ Complete fibrin degradation leads to normal peritoneal healing. Fibroblasts, by synthesizing collagen, play an active role in both peritoneal adhesions and striae formation. Incompletely degraded fibrin causes fibroblasts to produce collagen, and ineffective collagen degradation causes peritoneal adhesions. It is now known that collagen plays a major role in striae development. Thus, the development of striae gravidarum and adhesion formation are believed to share a common pathway and etiopathogenesis. ${ }^{6}$

According to Bibi et al, formation of both intra-peritoneal adhesions and striae gravidarum involve the protective role of elastin fibers and thus share almost similar pathway of tissue healing. ${ }^{7}$ The incidence of intra abdominal adhesions is quite low in patients with no history of prior abdominal surgery or cesarean section. The probability of adhesion formation has been reported to be $7 \%$ after primary cesarean delivery, rising to $68 \%$ following a third cesarean delivery. ${ }^{6}$

For women undergoing trial of vaginal delivery after previous cesarean section, uterine rupture is the most dreaded complication. ${ }^{8}$ In uterine rupture, there occurs a complete separation of all uterine layers with potential catastrophic consequences of hemorrhage and umbilical cord compression, leading to fetal and maternal vascular compromise. In the case of uterine dehiscence, the scarred lower uterine segment showed a higher collagen content along with a reduction of pan transforming growth factor-beta expression because of a marked decrease or absence of transforming growth factor-beta, a reduction of connective tissue growth factor, an increase in basic fibroblast growth factor and a slight enhancement in vascular endothelial growth factor, platelet-derived growth factor, and tumor necrosis factor-alpha expression. ${ }^{9}$ Uterine rupture (UR) is a rare $(0.3 \%)$ complication in the trial of labor after cesarean (TOLAC). ${ }^{10}$ Thus, it remains crucial to identify women with a high risk of uterine rupture when deciding on a repeat cesarean section (CS) or TOLAC.

The focus of the current paper is to establish the diagnostic efficacy of striae gravidarum with intraperitoneal adhesions and uterine scar thickness in women undergoing repeat cesarean section, as there is paucity in literature in showing the correlation of striae gravidarum with intra-peritoneal adhesions and uterine scar thickness.

Aim of the study was to find the diagnostic efficacy of striae gravidarum in predicting intra-peritoneal adhesions and uterine scar thickness in women undergoing repeat caesarean delivery. Objectives of the study were to score the striae gravidarum according to the Atwal numerical scoring system in women undergoing repeated caesarean delivery, to record the presence of intra-peritoneal adhesions via intra-operative grading through modified Nair's classification, to measure the uterine scar thickness intra-operatively in women undergoing repeat caesarean section.

\section{METHODS}

It was a cross-sectional study done over a period of 18 months duration. One hundred women with previous cesarean section scheduled for elective LSCS were enrolled after informed consent. Detailed history and clinical examination and investigations were done according to the hospital protocol. Striae gravidarum was calculated according to the Atwal numerical scoring system. The sites of examination included the four common sites of striae, i.e. abdomen, hips, breasts and thighs/buttocks. A scoring of maximum six was allotted at each site of striae; 0-3 for the number of striae present; 0-3 for the degree of erythema seen. The scoring of striae was numbered as follows: no striae- $0 ;<5$ striae-1; 5-10 striae-2; and $>10$ striae- 3 . The degree of erythema was scored as: no erythema-0; mild erythema (light red or pink)-1; marked erythema (dark red)-2; and violaceous erythema (purple)-3. The scores were then added up and out of a maximum of 24 , the women were divided into the following four groups. Women with a total score of 0 3 were graded as having 'none or no' significant striae, 49 'mild', 10-15 'moderate' and >16 'severe' striae. Old striae presents as silvery white striae that were present prior to pregnancy. Hence they were not included in the analysis. During elective caesarean section, intraoperatively, presence of intra-peritoneal adhesions were 
looked for and graded according to modified Nair scoring system. The modified Nair classification of intraoperative grading of IPAs defines intra-abdominal adhesions into five categories (0-4). Grade 0: Complete absence of adhesions. Grade 1, 2: Localized flimsy easily separable adhesions. Grade 3: Dense, extensive adhesions. Grade 4: Adhesions of the intestines to the abdominal wall or to the uterus OR dense adhesion of the uterus to the abdominal wall or rectovaginal pouch. After extraction of baby and before closing, the thickness of lower uterine segment at midpoint of lower flap of uterine incision is measured by metallic screw gauge.

\section{Inclusion criteria}

All patients undergoing elective repeat Caesarean section were included in the study.

\section{Exclusion criteria}

To avoid possible effects of the potential adhesion risk factors, patients with endometriosis, evidence of infective pelvic disease or any associated Tubo-ovarian mass, abdominal operations other than cesarean section such as an appendectomy, myomectomy and women in labor were excluded from the study.

\section{Outcome measures}

\section{Primary outcome measures}

Evaluation of striae gravidarum by Atwal numerical scoring system. Evaluation of intra-peritoneal adhesions according to Nair score. Measurement of lower segment uterine scar thickness intra-operatively

\section{Secondary Outcome Measures}

Correlation of time taken for anaesthesia induction to delivery interval with modified Nair score more than Grade 3. Correlation with bladder bowel injury. Correlation with requirement of Blood transfusion intraop or postoperatively. Correlation with NICU admission in baby and HDU admission in mother.

\section{Statistical analysis}

Categorical variables were presented in number and percentage $(\%)$ and continuous variables were presented as mean \pm SD and median. Normality of data was tested by Kolmogorov-Smirnov test. If the normality was rejected, then non parametric test was used. Following statistical tests were applied:

Quantitative variables were compared using MannWhitney Test (as the data sets were not normally distributed) between the two groups and Kruskal Wallis test was used for comparison between more than two groups. Qualitative variables were correlated using Fisher's Exact test and Spearman rank correlation coefficient was used to assess the correlation of various quantitative parameters. A $p$ value of $<0.05$ was considered statistically significant. The data was entered in MS EXCEL spreadsheet and analysis was done using Statistical Package for Social Sciences (SPSS) version 21.0.

\section{RESULTS}

Majority (68.00\%) of patients belonged to age group $\leq 30$ years. Age in years was $\geq 30$ in only 32 out of 100 patients. Mean value of age in years of study subjects was $29.06 \pm 3.1$. Further, in majority $(60.00 \%)$ of patients, SG score was of mild degree followed by no significant striae $(36.00 \%)$. SG score was of moderate degree in only 4 out of 100 patients. In majority $(65.00 \%)$ of patients, Nair score grade was 1, 2 followed by grade $0(20.00 \%)$ and grade $3(13.00 \%)$. Nair score grade was 4 in only 2 out of 100 patients. Majority $(93.00 \%)$ of patients did not require blood transfusion. Blood transfusion was required in only 7 out of 100 patients. Further, in majority $(92.00 \%)$ of patients, NICU/HDU stay was not required and Bladder-bowel injury was present in only $2(2 \%)$ out of 100 patients.

Table 1: Descriptive statistics.

\begin{tabular}{|l|l|}
\hline Variable & Mean \pm SD \\
\hline LUS scar thickness $(\mathbf{m m})$ & $3.74 \pm 0.87$ \\
\hline Induction-delivery interval (in minutes) & $32.4 \pm 9.58$ \\
\hline SG Score & $4.79 \pm 2.77$ \\
\hline
\end{tabular}

Mean value of LUS scar thickness (mm) of study subjects was $3.74 \pm 0.87$. Mean value of anaesthesia inductiondelivery interval (in minutes) of study subjects was 32.4 \pm 9.58 . Mean value of SG score of study subjects was $4.79 \pm 2.77$.

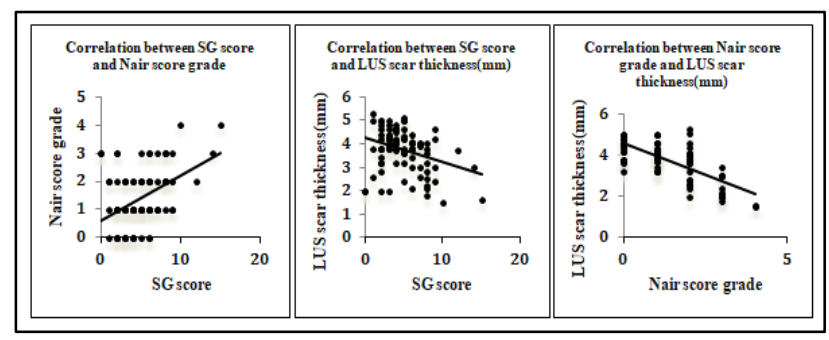

Figure 1: Correlation of LUS scar thickness, Nair score grade and SG score with each other.

Significant positive correlation was seen between Nair score grade with SG score with correlation coefficient of 0.379 ( $\mathrm{p}<0.05)$. Significant negative correlation was seen between LUS scar thickness $(\mathrm{mm})$ with SG score $(\mathrm{p}<0.05)$ and Nair score grade $(\mathrm{p}<0.05)$ with correlation coefficient of -0.277 and -0.602 respectively. Further, significant negative correlation was seen between LUS scar thickness $(\mathrm{mm})$ with anaesthesia induction-delivery interval (in minutes) $(r=-0.645 ; \mathrm{p}<0.0001)$. 
Table 2: Association between SG score and various parameters.

\begin{tabular}{|c|c|c|c|c|c|}
\hline & & $\begin{array}{l}\text { No significant striae } \\
(\mathrm{n}=36)\end{array}$ & $\begin{array}{l}\text { Mild striae } \\
(\mathrm{n}=60)\end{array}$ & $\begin{array}{l}\text { Moderate striae } \\
(\mathrm{n}=4)\end{array}$ & P-value \\
\hline \multirow{8}{*}{ Nair score grade } & \multirow{2}{*}{ Grade 0} & 13 & 7 & 0 & \multirow{8}{*}{$<0.0001$} \\
\hline & & $36.11 \%$ & $11.67 \%$ & $0 \%$ & \\
\hline & \multirow{2}{*}{ Grade 1,2} & 19 & 45 & 1 & \\
\hline & & $52.78 \%$ & $75 \%$ & $25 \%$ & \\
\hline & \multirow{2}{*}{ Grade 3} & 4 & 8 & 1 & \\
\hline & & $11.11 \%$ & $13.33 \%$ & $25 \%$ & \\
\hline & \multirow{2}{*}{ Grade 4} & 0 & 0 & 2 & \\
\hline & & $0 \%$ & $0 \%$ & $50 \%$ & \\
\hline LUS scar thickness (mm) & Mean \pm SD & $3.86 \pm 0.92$ & $3.75 \pm 0.77$ & $2.45 \pm 1.08$ & 0.025 \\
\hline $\begin{array}{l}\text { Induction-delivery interval (in } \\
\text { minutes) }\end{array}$ & Mean \pm SD & $31.25 \pm 10.6$ & $31.92 \pm 7.45$ & $50 \pm 13.83$ & 0.015 \\
\hline \multirow{4}{*}{$\begin{array}{l}\text { Requirement of blood } \\
\text { transfusion }\end{array}$} & \multirow{2}{*}{$\begin{array}{l}\text { 1BT done } \\
\text { post-op }\end{array}$} & 1 & 3 & 3 & \multirow{4}{*}{0.001} \\
\hline & & $2.78 \%$ & $5 \%$ & $75 \%$ & \\
\hline & \multirow{2}{*}{ None } & 35 & 57 & 1 & \\
\hline & & $97.22 \%$ & $95 \%$ & $25 \%$ & \\
\hline \multirow{4}{*}{ NICU/HDU stay } & \multirow{2}{*}{ None } & 33 & 57 & 2 & \multirow{4}{*}{0.027} \\
\hline & & $91.67 \%$ & $95 \%$ & $50 \%$ & \\
\hline & \multirow{2}{*}{ Yes } & 3 & 3 & 2 & \\
\hline & & $8.33 \%$ & $5 \%$ & $50 \%$ & \\
\hline \multirow{4}{*}{ Bladder-bowel injury } & \multirow{2}{*}{ None } & 36 & 60 & 2 & \multirow{4}{*}{0.001} \\
\hline & & $100 \%$ & $100 \%$ & $50 \%$ & \\
\hline & \multirow{2}{*}{ Present } & 0 & 0 & 2 & \\
\hline & & $0 \%$ & $0 \%$ & $50 \%$ & \\
\hline
\end{tabular}

Table 3: Association between Nair Score Grade and various parameters.

\begin{tabular}{|c|c|c|c|c|c|c|}
\hline & & $\begin{array}{l}\text { Grade } 0 \\
(n=20)\end{array}$ & $\begin{array}{l}\text { Grade 1, } 2 \\
(n=65)\end{array}$ & $\begin{array}{l}\text { Grade } 3 \\
(n=13)\end{array}$ & $\begin{array}{l}\text { Grade } 4 \\
(n=2)\end{array}$ & P-value \\
\hline $\begin{array}{l}\text { Induction-delivery } \\
\text { interval (in minutes) }\end{array}$ & Mean \pm SD & $24.55 \pm 3.98$ & $31.22 \pm 5.84$ & $46 \pm 10.08$ & $61 \pm 4.24$ & $<0.0001$ \\
\hline \multirow{4}{*}{$\begin{array}{l}\text { Requirement of blood } \\
\text { transfusion }\end{array}$} & \multirow{2}{*}{ 1BT done post-op } & 0 & 1 & 4 & 2 & \multirow{4}{*}{$<0.0001$} \\
\hline & & $0 \%$ & $1.54 \%$ & $30.77 \%$ & $100 \%$ & \\
\hline & \multirow{2}{*}{ None } & 20 & 64 & 9 & 0 & \\
\hline & & $100 \%$ & $98.46 \%$ & $69.23 \%$ & $0 \%$ & \\
\hline \multirow{4}{*}{ NICU/HDU stay } & \multirow{2}{*}{ None } & 20 & 65 & 7 & 0 & \multirow{4}{*}{$<0.0001$} \\
\hline & & $100 \%$ & $100 \%$ & $53.85 \%$ & $0 \%$ & \\
\hline & \multirow{2}{*}{ Yes } & 0 & 0 & 6 & 2 & \\
\hline & & $0 \%$ & $0 \%$ & $46.15 \%$ & $100 \%$ & \\
\hline \multirow{4}{*}{ Bladder-bowel injury } & \multirow{2}{*}{ None } & 20 & 65 & 13 & 0 & \multirow{4}{*}{$<0.0001$} \\
\hline & & $100 \%$ & $100 \%$ & $100 \%$ & $0 \%$ & \\
\hline & \multirow{2}{*}{ Present } & 0 & 0 & 0 & 2 & \\
\hline & & $0 \%$ & $0 \%$ & $0 \%$ & $100 \%$ & \\
\hline $\begin{array}{l}\text { Induction-delivery } \\
\text { interval (in minutes) }\end{array}$ & Mean \pm SD & $29.65 \pm 6.14$ & & $48 \pm 10.78$ & & $<0.0001$ \\
\hline
\end{tabular}

Significant association was seen in the distribution of Nair score grade with SG score $(\mathrm{p}<0.05)$; LUS scar thickness $(\mathrm{mm})$ with SG score $(\mathrm{p}<0.05)$; anaesthesia induction-delivery interval (in minutes) with SG Score ( $<<0.05)$; requirement of blood transfusion with SG Score $(\mathrm{p}<0.05)$; NICU/HDU stay with SG Score $(\mathrm{p}<0.05)$; and bladder-bowel injury with SG Score $(\mathrm{p}<0.05)$.
Significant association was seen in anaesthesia inductiondelivery interval (in minutes) with Nair Score Grade $(\mathrm{p}<0.05)$; requirement of blood transfusion with Nair Score Grade $(\mathrm{p}<0.05)$; NICU/HDU stay with Nair Score Grade $(p<0.05)$; bladder-bowel injury with Nair Score Grade $(\mathrm{p}<0.05)$; and anaesthesia induction-delivery interval (in minutes) with Nair Score Grade $(\mathrm{p}<0.05)$. 
Table 4: Association between LUS scar thickness and various parameters.

\begin{tabular}{|c|c|c|c|}
\hline & & $\begin{array}{l}\text { LUS scar } \\
\text { thickness } \\
(\mathrm{mm})\end{array}$ & $\begin{array}{l}\text { P- } \\
\text { value }\end{array}$ \\
\hline \multirow{2}{*}{$\begin{array}{l}\text { Requirement } \\
\text { of Blood } \\
\text { Transfusion }\end{array}$} & None $(n=93)$ & $3.84 \pm 0.78$ & \multirow[b]{2}{*}{0.001} \\
\hline & $\begin{array}{l}\text { 1BT done } \\
\text { post-op }(\mathrm{n}=7)\end{array}$ & $2.37 \pm 0.96$ & \\
\hline \multirow{2}{*}{$\begin{array}{l}\text { NICU/HDU } \\
\text { stay }\end{array}$} & None $(n=92)$ & $3.87 \pm 0.76$ & \multirow{2}{*}{$<0.0001$} \\
\hline & Yes $(n=8)$ & $2.23 \pm 0.66$ & \\
\hline \multirow{2}{*}{$\begin{array}{l}\text { Bladder- } \\
\text { bowel injury }\end{array}$} & None $(n=98)$ & $3.79 \pm 0.82$ & \multirow{2}{*}{0.015} \\
\hline & Present $(n=2)$ & $1.55 \pm 0.07$ & \\
\hline
\end{tabular}

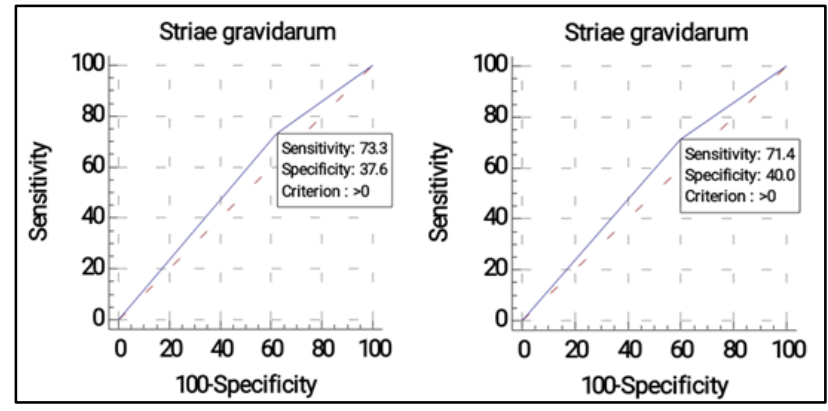

Figure 2: ROC curve of SG for predicting Nair Score Grade 3/4 (Left-side) and LUS scar thickness (Rightside).

Table 5: ROC Curve of SG for predicting Nair Score Grade 3/4 and LUS scar thickness.

\begin{tabular}{|lll|}
\hline Striae gravidarum & Nair Score Grade $3 / 4$ & LUS scar thickness $(<3.74 \mathbf{m m})$ \\
\hline Area under the ROC curve & 0.555 & 0.557 \\
\hline Standard error & 0.0647 & 0.0494 \\
\hline 95\% Confidence interval & 0.452 to 0.654 & 0.454 to 0.656 \\
\hline P value & 0.3964 & 0.2472 \\
\hline Sensitivity(95\% CI) & $73.33 \%(44.9-92.2 \%)$ & $71.43 \%(53.7-85.4 \%)$ \\
\hline Specificity(95\% CI) & $37.65 \%(27.4-48.8 \%)$ & $40 \%(28.0-52.9 \%)$ \\
\hline PPV(95\% CI) & $17.2 \%(8.9-28.7 \%)$ & $39.1 \%(27.1-52.1 \%)$ \\
\hline NPV(95\% CI) & $88.9 \%(73.9-96.9 \%)$ & $72.2 \%(54.8-85.8 \%)$ \\
\hline Diagnostic accuracy & $43.00 \%$ & $51.00 \%$ \\
\hline
\end{tabular}

Significant association was seen in LUS scar thickness $(\mathrm{mm})$ with requirement of blood transfusion $(\mathrm{p}<0.05)$; LUS scar thickness $(\mathrm{mm})$ with NICU/HDU stay $(\mathrm{p}<0.05)$; and LUS scar thickness $(\mathrm{mm})$ with bladder-bowel injury $(\mathrm{p}<0.05)$.

ROC curves above the diagonal line are considered to have reasonable discriminating ability to predict Nair Score Grade 3/4. Interpretation of the area under the ROC curve showed that the performance of striae gravidarum (AUC 0.555 ; $95 \%$ CI: 0.452 to 0.654 ) for Nair Score Grade 3/4 was non-significant. On the other hand, Interpretation of the area under the ROC curve showed that the performance of striae gravidarum (AUC 0.557 ; 95\% CI: 0.454 to 0.656 ) for LUS Scar Thickness was non-significant.

\section{DISCUSSION}

The study found that the majority of the patients were aged between 21 and 30 years. This implied that most of the young population was affected by Striae Gravidarum. The mean age in the current study of the included patients was $29.06 \pm 3.1$ years. On the other hand, Celik et al found that the average age of the patients was $28.66 \pm 1.00$ years. Further, in the current study the mean uterine scar thickness (in mm) for no striae, mild striae and moderate striae was found to be $3.864 \pm 0.92,3.753 \pm .7745$ and $2.450 \pm 1.08$ respectively. However, according to the study of Gungor et al the mean uterine scar thickness (in $\mathrm{mm}$ ) in the no $\mathrm{SG}$, mild $\mathrm{SG}$ and severe $\mathrm{SG}$ groups were $3.82 \pm 4.04,5.20 \pm 4.13$ and $5.18 \pm 3.52$, respectively. ${ }^{11,12}$ Thus, there was statistically significant difference in the mean value of LUS scar thickness between No Striae, Mild Striae and Moderate Striae, which was contradictory to the study of Gungor et al. ${ }^{12}$ The current study found that there was statistically significant association between intraperitoneal adhesion and Striae Gravidarum. This implies that if Striae Gravidarum will be more, the chances of intraperitoneal adhesion increases manifolds. It is similar to the results of Dogan et al and Gungor et al. ${ }^{6,12}$ Finally, the current study found that the majority of the patients had mild striae with no striae on the next place and the lowest among them with moderate striae. On the contrary, Celik et al found that the majority of patients had severe striae, with second highest number of patients having no striae. ${ }^{11}$

\section{CONCLUSION}

In the light of the above results, it has been found that the Striae gravidarum is a common form of gestational change that can be a substantial source of distress. Despite the identification of risk factors, prevention of SG remains challenging. Various therapies have been used to improve the appearance of SG. Furthermore, it was found in the study that the SG status of a patient with a previous Caesarean section and no prior abdominal operation history might help predict IPA status before planning a new operation. The study showed a negative 
association between the LUS scar thickness and SG grade. Therefore, more the SG less will be the scar thickness and vice-versa. Moreover, statistically significant associations have been between SG, BT requirement, intraperitoneal adhesion, and NICU stay. Also, the study found statistically significant difference in the anaesthesia induction-delivery time between No Striae, Mild Striae and Moderate Striae.

\section{Recommendations}

Striae gravidarum is a common disfiguring cosmetic concern, afflicting a vast majority of the pregnant patients. Striae gravidarum can be considered as a useful predictor of unforeseeable intraoperative complications such as intraperitoneal adhesions, LUS thickness, requirement of blood transfusion, risk of bladder-bowel injury and chances of NICU admission of neonate or HDU admission of mother. Scoring the SG in a patient preoperatively will attribute to better anticipation and preparedness for the above mentioned complications, leading to better management of the patient, especially in terms of arranging adequate blood products, surgeon with adequate expertise, arrangement of NICU/HDU bed preoperatively. Striae gravidarum scoring is a zero-cost simple quick and easy technique which can be universally used with very minimal intra-observer variation to predict grave intraoperative complications, thereby reducing maternal and neonatal morbidity and mortality, especially in low resource settings. Striae gravidarum is not a diagnostic indicator for predicting intraperitoneal adhesions or uterine scar thickness but it can be quite useful as a screening method in low resource settings due to its moderately high sensitivity but low specificity.

\section{ACKNOWLEDGMENTS}

Authors would like to thank to Dr. Anjali Dabral, Professor, Head of Department of Obstetrics and Gynecology, VMMC and Safdarjung Hospital, New Delhi and to all the consultants, specialists, senior residents and colleagues for their support during the study.

\section{Funding: No funding sources}

Conflict of interest: None declared

Ethical approval: The study was approved by the Institutional Ethics Committee

\section{REFERENCES}

1. Salter SA, Batra RS, Rohrer TE, Kohli N, Kimball AB. Striae and pelvic relaxation: two disorders of connective tissue with a strong association. J Invest Dermatol. 2006;126:1745-8.
2. Liu L, Huang J, Wang Y, Li Y. Risk factors of striae gravidarum in Chinese primiparous women. PLoS ONE. 2018;13(6):e0198720.

3. Atwal GSS, Manku LK, Griffiths CEM, Polson DW. Striae gravidarum in primiparae. British J Dermatol. 2006;155:965-9.

4. Farahnik B, Park K, Korumpouzos G, Murase J. Striae gravidarum: risk factors, prevention, and management. Int J Womens Dermatol. 2017;3(2):7785.

5. Awonuga AO, Fletcher NM, Saed GM, Diamond MP. Postoperative adhesion development following cesarean and open intra-abdominal gynecological operations: a review. Reprod Sci. 2011;18(12):116685.

6. Dogan A, Ertas IE, Uyar I, Karaca I, Bozgeyik B, Toz E, Ozeren M. preoperative association of abdominal striae gravidarum with intraabdominal adhesions in pregnant women with a history of previous cesarean section: a cross sectional study. Geburtshilfe Frauenheilkd. 2016;76(3):268-72.

7. Bibi I, Majeed S, Hussain HN. Relation of striae gravidarum with cesarean scar and peritoneal adhesions. J Med Physiol Biophysics. 2018;49:10712.

8. Landon MB. Predicting uterine rupture in women undergoing trial of labor after prior cesarean delivery. Seminars in Perinatology. 2010;34(4):26771.

9. Buhimschi CS, Buhimschi IA, Yu C, Wang H, Sharer DJ, Diamond MP, et al. The effect of dystocia and previous cesarean uterine scar on the tensile properties of the lower uterine segment. Am J Obstet Gynecol. 2006;194:873-83.

10. Pollio F, Staibano S, Mascolo M, Salvatore G, Persico F, De Falco M, Di Lieto A. Uterine dehiscence in term pregnant patients with one previous cesarean delivery: Growth factor immunoexpression and collagen content in the scarred lower uterine segment. Am Obst Gynecol. 2006;194(2):527-34.

11. Celik EY, Ersoy AO, Ersoy E, Yoruk O, Tokmak A, Tasci Y. Is striae gravidarum related to cesarean scar and peritoneal adhesions? Pak J Med Sci. 2018;34(3):568-73.

12. Gungor ANC, Oguz S, Hacivelioglu S, Isik S, Uysal $A$, Gencer $M$, et al. Predictive value of striae gravidarum severity for intraperitoneal adhesions or uterine scar healing in patients with previous caesarean delivery. J Maternal Fetal Neonatal Med. 2013;27(13):1312-5.

Cite this article as: Mohanty A, Anand HP. Diagnostic efficacy of Striae Gravidarum in predicting intraperitoneal adhesions and uterine scar thickness in women undergoing repeat caesarean section. Int J Reprod Contracept Obstet Gynecol 2021;10:582-7. 